\title{
Using a Market-Utility-Based Approach to Designing Public Services: A Case Illustration from United States Forest Service
}

\author{
Rohit Verma \\ Associate Professor of Service Operations Management, School of Hotel Administration, Cornell \\ University, Ithaca NY 14853, USA \\ Jordan J. Louviere \\ School of Marketing, University of Technology, Sydney NSW 2007, Australia \\ Paul Burke \\ School of Marketing, University of Technology, Sydney NSW 2007, Australia
}

Government and public services have to not only enforce the requirements of the regulatory policies, but also have to satisfy the needs of preferences of their clients and customers. In this paper, we summarize the results of a multi-year case study conducted to assess the choices of campground users at the Shawnee National Forest (Illinois), which is managed by United States Forest Service. The results show how users' tradeoff between location, capacity-related and pricing attributes when choosing a campground. The case study provides guidance for design and development of new services and more effective management of effective resources within the national forest.

\section{Introduction}

Government agencies and public organizations (e.g. postal services, forest service, national parks service and internal revenue service) in a more complex environment than commercial firms because they are responsible for imposing/enforcing regulatory measures. In addition, government agencies exist to fulfill specific mission(s) within the domain of public laws (or equivalent) and therefore "profit-maximizing" or "cost minimization" is often not the main objective for their existence. While the governance and financial performance of government agencies are widely discussed in news magazines, their unique operational characteristics and constraints rarely get the attention they deserve (e.g. Keating and Frumkin, 2001). At the same time, because of shrinking funding levels, deregulation and competition from for-profit companies and not-for-profit organizations, many government agencies experience increased pressure to maximize the limited resources available to them in successfully fulfilling their specified mission. Managers in government agencies are increasingly asked to present strong "business cases" for additional and continuing funding requests. 
Therefore, it is crucial for government agencies to critically evaluate the needs and preferences of their "customers" and accordingly focus/align their operational resources.

The purpose of this paper therefore is to illustrate the usefulness of market-utility-based approach for effectively designing government and public services. Recent studies have demonstrated that market-utility-based framework, especially discrete choice analysis (DCA), is very effective in understanding customer needs and preferences when exploring new service designs (e.g. Easton and Pullman, 2001; Verma et al., 2001; Goodale et al., 2003; lqbal et al., 2003). For example, based on discrete choice data collected at a large international airport, Pullman et al. (2001) developed a framework matching the needs of multiple market segments with service offerings. Easton and Pullman (2001) developed a mathematical modeling formulation of the sellers' utility problem within the context of new service design using discrete choice data. Verma et al. (2001) presented a non-linear optimization model linking customer preferences obtained from discrete choice analysis, production cost and operating difficulty. Using discrete choice data collected from over 2000 customers across the United States, Iqbal et al. (2003) tested the impact of usage familiarity on various features of transaction-based e-services.

While market-utility-based approaches have been applied to various service design problems such as examples cited earlier, we rarely see published examples of their use in government and not-for-profit services. The case illustration presented in this paper is based on a study of user preferences for campgrounds at a large United States based National Forest (Shawnee National Forest, Illinois) using field-based rigorous qualitative and DCA-based empirical data collected from 249 customers and several forest service staff members.

Specifically, the case study presented in this paper demonstrates how the visitors to a national forest tradeoff price, location and operational characteristics when choosing a campground. While some of the unique geological characteristics of a region cannot be altered much by humankind, the price (nightly fee, day-use fees and discounts during extended stays) and operational features (e.g. capacity, reservation options, occupancy) can have significant impact on how visitors choose a campground. National Forest visitor preferences for locationrelated characteristics (e.g. proximity to natural water body, rugged hills, green valley, etc.) or outdoor activities (e.g. hunting, horse riding, physical/ water-based recreation) can also provide guidelines for selecting sites for development of campgrounds.

Because of shrinking funding levels and because of increased emphasis on operational efficiencies, government and public agencies such as US Forest Service have to prioritize the use of resources allocated to them. We believe that use of rigorous market-utility-based approach, such as the example presented in this paper, can assist in aligning the operations strategy of government and public organizations with the needs and preferences of the users of their services. While the case illustration presented is specific to US Forest Service, we believe that similar approach can be easily implemented by other government and public organizations. 
The rest of the paper is organized as follows: first, we briefly describe the background information related to the context of the case study-Shawnee National Forest; second, we describe the research methodology; third, we discuss the results and provide managerial recommendations; fourth, we conclude and provide directions for future research.

\section{Background Information}

According to the United States Forest Service Web site

(http://www.fs.fed.us/r9/forests/shawnee/), the origin of the Shawnee National Forest is closely linked to the economic calamity of the Great Depression. The southern Illinois economy was on the skids well before the stock market crash of 1929. Decades of timber exploitation, subsistence farming and wildfires resulted in massive erosion, declining soil fertility and a downward spiral in crop production. Non-agricultural jobs were centered in the timber and mining industries, both of which experienced significant market downturns throughout the 1920s. Upstate newspapers, principally the Chicago Tribune, began campaigning for the establishment of a national forest in Illinois. By 1931, the Illinois Department of Conservation and the Illinois Natural History Survey had pushed consent language through the State Legislature. This provided broad authority to the United States to establish, consolidate and extend national forests within the state without any limitation of acreage or approval by local or state agencies.

Fig. 1 shows the location/map of Shawnee National Forest within the state of Illinois, USA. In contrast to the gently rolling farm lands of the north, the more than 270,000 acres of the Shawnee National Forest is located in southern Illinois between Ozark and Shawnee Hills between Mississippi and Ohio rivers. Popular geological attractions within the national forest include Garden of the Gods, Stone Face, Little Grand Canyon and their hiking trails. Within the national forest $10 \%$ of the area is designated as "wilderness". The primary purpose of wilderness management is to preserve natural ecosystems and its character for future generations and to provide wilderness-experience in a natural appealing environment to visitors. All of the seven designated wilderness areas within the Shawnee National Forest are open to visitors; however, the use of motorized vehicle or mechanical equipments.

The Shawnee National Forest also includes abundance of recreational opportunities to visitors such as hiking, horse riding, fishing, boating, hunting and camping among others. There are over 1250 miles of paved, gravel, dirt and grass roads within the forest are open for foot travel, mountain bikers and for horse riding. The national forest and surrounding areas include a number of natural water bodies ranging from small ponds to around 7000 acres of lakes. These locations offer boating, fishing and swimming opportunities for visitors. Within the Shawnee National Forest there are three swimming "beaches" at Lake Glendale, Pounds Hollow and Johnson Creek. In addition, Lake Glendale and Pounds Hollow beaches are operated by a concessionaire where lifeguards, food, drinks and rentals are available.

Camping opportunities within the Shawnee National Forest are plentiful ranging from 
Fig. 1. Shawnee National

Forest, Illinois (USA)

[Source: United State Forest

Service Web site].

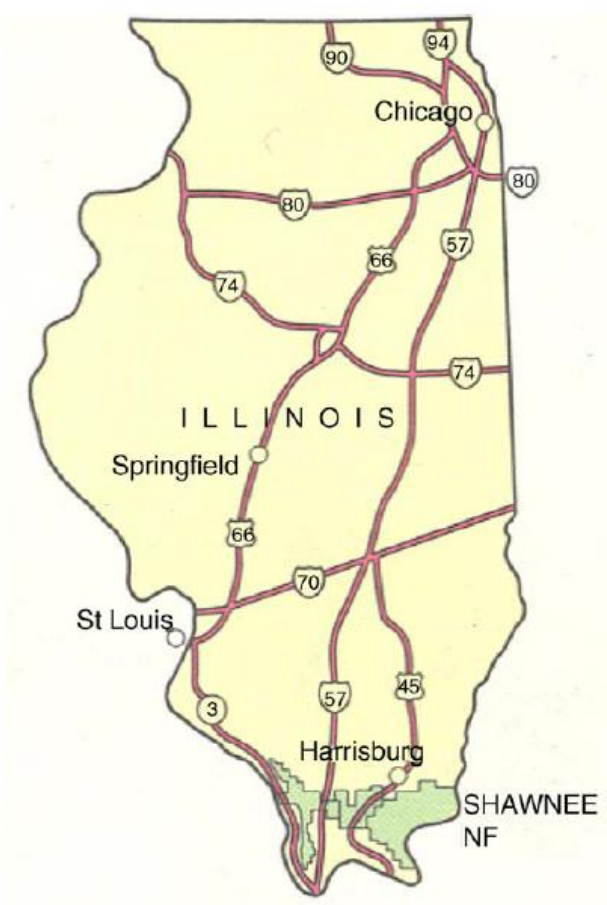

rugged sites to fully developed campgrounds. Most of the 12 campgrounds located within the national forest include drinking water, restrooms, picnic tables and grills/fire rings. However, showers are only available at Oak Point Campground located near the Lake Glendale recreational area. In addition, several campsites at Oak Point also include electrical hookups for use in recreational vehicles. The campgrounds are scattered across the national forest with capacities ranging from less than 10 to over 75 . The fee for staying at campgrounds varies from US\$ 7 to 10 per night depending on the location and the level of development. Usage fees at campgrounds ranged from US\$ 0 to 5 for visitors who only wanted to stay there during the day (e.g. for picnicking).

With continued growth in outdoor recreational activities during the last decade, campgrounds and other public facilities within the national forest have started facing capacity problems during the major holidays and long weekends. While it is possible for for profit corporations to use revenue management techniques and charge a premium for services during high demand period, such practices cannot easily be forced on government and public organizations. In addition to adding capacity, the management also needs to understand visitors' needs and preferences with respect to campground locations within the national forest with respect to proximities to various recreational activities and natural environment. Therefore, a key challenge for the Shawnee National Forest was to assess the necessity for adding capacity at existing campgrounds and/or to develop and open new campgrounds. All such decisions require additional resources for which funding requests will have to be approved by senior federal officials. Therefore, the main objective of this case study was to assess the preferences of Shawnee National Forest visitors so that appropriate operational decisions could be made. 


\section{Research Methodology}

Approach

An effective method for determining the market based relative value of various features of a service (e.g. campgrounds) involves modeling consumer preferences in response to experimentally designed service profiles. This approach, commonly known as probabilistic discrete choice analysis (DCA) has been used to model choice processes of decision-makers in a variety of academic disciplines, including marketing, operations management, transportation, urban planning, hospitality and natural resource economics (e.g. Louviere and Timmermans, 1990; McFadden, 1986; Pullman and Moore, 1999; Verma et al., 1999).

Statistical models (e.g. multinomial logit models, nested logit models) developed from a DCA study link service attributes to consumer preferences. Therefore, by describing a service in terms of appropriate attributes, DCA can be used to predict relative market impact of various services offering (e.g. Danaher, 1997). Recent papers by Verma et al. (1999) and Louviere and Timmermans (1990) review DCA literature and provide guidelines for designing and conducting DCA studies for services. Rather than repeating what has already been detailed in various publications; here, we only briefly describe the DCA method.

Discrete choice experiments involve careful design of service profiles (e.g. a specific campground) and choice sets (a number of campground alternatives) in which two or more service alternatives are offered to decision-makers and they are asked to evaluate the options and choose one (or none). Each participant in a DCA experiment typically receives several choice sets to evaluate (e.g. 8-32 sets) with two or more hypothetical services to choose from in each set. The design of the experiment is under the control of the researcher, and consequently, the decision-makers' choices (dependent variable) are a function of the attributes of each alternative, personal characteristic of the respondents and unobserved effects captured by the random component (e.g. unobserved heterogeneity or omitted factors). For a detailed theoretical and statistical background of DCA please refer to Ben- Akiva and Lerman (1991), Loiuviere et al., 2001 and McFadden (1986).

DCA applications based on choice experiments typically involve the following steps: (1) identification of attributes, (2) specification of attribute levels, (3) experimental design, (4) presentation of alternatives to respondents and (5) estimation of the choice model. Past studies have shown that in general, the market share predictions generated from the statistical models (e.g. multinomial logit, MNL) based on discrete choice analysis are extremely accurate (BenAkiva and Lerman, 1991; Loiuviere et al., 2001). Next, we describe our implementation of DCA within the context of campground selection by visitors in Shawnee National Forest.

\section{Campground attributes and experimental design}

As recommended by other researchers, we first conducted extensive qualitative research before finalizing the experimental attributes and their levels within the discrete choice 
experiments included within the customer surveys (Verma et al., 1999). We interviewed US Forest Service officials located in the North Central Research Station (located in Chicago, IL metropolitan area), and a number of field officers posted at various Shawnee National Forest locations. We also interviewed a number of campers staying different campgrounds within the national forest. Based on qualitative data and a review of academic and practitioner's literature on the topic we identified nine attributes of campgrounds to be varied in discrete choice experiments. The nine attributes can be broadly classified within broad three categoriescampground location, capacity and usage fees.

The "location" construct consisted of three attributes-campground location, location of campsite within a campground and proximity to recreational activities close to the campground. Four experimental levels were identified for the "campground location" attribute, which include-rugged hills, natural water body, green valley and unique geological area. "Campsite location" was varied as two-level attribute-campsites in an open area and campsites separated by trees/bushes. The four experimental levels for the "proximity to recreational activities" attribute were hunting, horse riding, physical activities and waterrelated activities. Table 1 describes all the attributes and their levels.

The "capacity" construct was represented by campground size, campground occupancy and advanced reservations options. Both campground size and occupancy were represented by four experimental levels each and reservation option was designed as a three-level attribute. The third construct "fees" was represented by nightly fee, day-use fee and discount for third night stay. The nightly and day-use fees were four level attributes whereas discount was represented as a two-level attribute.

After finalizing the list of attributes and their experimental levels, we experimentally designed eight statistically equivalent groups of 32 campground profiles that allowed us to reliably estimate all the main effects of the campground attributes (Loiuviere et al., 2001). To enhance the realism of the task, a full profile approach was used in presenting the choice sets (Green and Srinivasan, 1990), i.e. each profile shown to the respondents simultaneously described some combination of all the attributes.

We pre-tested the survey with 25 randomly selected campers to ensure ease and comprehension of the task, as well as to ensure reliable data collection methods. Average task completion time was approximately $20 \mathrm{~min}$ and respondents did not indicate difficulty in comprehension.

In addition to the campground choice task, the survey instrument included several questions about respondents' past camping trips and demographics. We will describe summarized results in the next section.

\section{Sampling Frame and Data Collection}

The population of interest was campers and day-use visitors at one of the 15 federal or 


\begin{tabular}{|c|c|c|}
\hline Constructs & Attributes & Levels \\
\hline \multirow[t]{3}{*}{ Location } & Campground location & $\begin{array}{l}\text { (1) Rugged hills } \\
\text { (2) Natural water body } \\
\text { (3) Green valley } \\
\text { (4) Unique geological features }\end{array}$ \\
\hline & Campsite location & $\begin{array}{l}\text { (1) Campsites in open area } \\
\text { (2) Campsites separated by bushes/trees }\end{array}$ \\
\hline & Activities close to campground location & $\begin{array}{l}\text { (1) Hunting } \\
\text { (2) Horse riding } \\
\text { (3) Physical activities } \\
\text { (4) Water activities }\end{array}$ \\
\hline \multirow[t]{3}{*}{ Capacity } & Campground size & $\begin{array}{l}\text { (1) } 120 \text { Campsites } \\
\text { (2) } 90 \text { Campsites } \\
\text { (3) } 60 \text { Campsites } \\
\text { (4) } 30 \text { Campsites }\end{array}$ \\
\hline & Campground occupancy & $\begin{array}{l}\text { (1) } 20 \% \text { or less occupied } \\
\text { (2) } 40 \% \text { occupied } \\
\text { (3) } 60 \% \text { occupied } \\
\text { (4) } 80 \% \text { or more occupied }\end{array}$ \\
\hline & Advance reservation fee & $\begin{array}{l}\text { (1) Not available } \\
\text { (2) US\$ } 3 \\
\text { (3) US\$ } 6\end{array}$ \\
\hline \multirow[t]{3}{*}{ Fee } & Daily use fees & $\begin{array}{l}\text { (1) US\$ } 9 \\
\text { (2) US\$ } 6 \\
\text { (3) US\$ } 3 \\
\text { (4) None }\end{array}$ \\
\hline & Nightly fees & $\begin{array}{l}\text { (1) US\$ } 10 \\
\text { (2) US\$ } 8 \\
\text { (3) US\$ } 6 \\
\text { (4) US\$ } 4\end{array}$ \\
\hline & Discount on third night stay & $\begin{array}{l}\text { (1) None } \\
\text { (2) } 50 \% \text { discount for third night stay }\end{array}$ \\
\hline
\end{tabular}

Table 1 Experimental constructs, attributes, and levels

state campgrounds located in the Shawnee National Forest during heavy usage periods (Labor Day and Memorial Day weekends). Twelve interviewers were available during each sampling day. By balancing the total interviewing time available with the size of the campground we developed a weighted plan to get a representative sample from the entire national forest. In addition, interviewing times were varied daily at each campground to reduce any additional biases.

The interviewers walked to each campsite within the campground and requested the campers to complete the survey. Each potential respondent was offered an incentive to participate in a raffle to win 1 of the 10 US\$ 100 gift checks by participating in the survey. If the camper agreed to participate in the survey then the interviewer offered to wait and collect the completed response right away. A small number of campers either asked the campers to return back later to collect the surveys or choose the mail the survey back later using postage paid envelope. 


\section{Results and Analysis}

After data collection during Labor Day and Memorial Day weekends the final sample size was for the study was 249 . The average age of the respondent was 41 years with a standard deviation of 12 years. Approximately $40 \%$ of the respondents were female and approximately $30 \%$ had at least a 4-year college degree. The annual household income for over $70 \%$ of the respondents was between US\$ 25,000 and 100,000 . Approximately $80 \%$ of the camping party included 1 or more children 12 years or younger and approximately $40 \%$ included at least one person 65 years or older. About two-thirds of the camping parties were staying in tents and the remaining were planning to stay in a recreational vehicle.

\begin{tabular}{|c|c|c|c|c|}
\hline Constructs & Attributes & Levels & Relative beta weights & Relative main effect \\
\hline \multirow[t]{10}{*}{ Location } & \multirow[t]{4}{*}{ Campground location } & Rugged hills & 0.931 & \multirow[t]{4}{*}{0.807} \\
\hline & & Natural water body & 0.267 & \\
\hline & & Green valley & 0.142 & \\
\hline & & Unique geological features & 0.574 & \\
\hline & \multirow[t]{2}{*}{ Campsite location } & Campsites in open area & 0.300 & \multirow[t]{2}{*}{0.365} \\
\hline & & Campsites separated by bushes/trees & 0.657 & \\
\hline & Activities close to & Hunting & 0.010 & \multirow[t]{4}{*}{0.895} \\
\hline & \multirow[t]{3}{*}{ Campground location } & Horse riding & 0.624 & \\
\hline & & Physical activities & 0.884 & \\
\hline & & Water activities & 0.393 & \\
\hline \multirow[t]{11}{*}{ Capacity } & \multirow[t]{4}{*}{ Campground size } & 120 Campsites & 0.581 & \multirow[t]{4}{*}{0.625} \\
\hline & & 90 Campsites & 0.370 & \\
\hline & & 60 Campsites & 0.175 & \\
\hline & & 30 Campsites & 0.785 & \\
\hline & \multirow[t]{4}{*}{ Campground occupancy } & $20 \%$ or less occupied & 0.551 & \multirow[t]{4}{*}{0.814} \\
\hline & & $40 \%$ occupied & 0.099 & \\
\hline & & $60 \%$ occupied & 0.370 & \\
\hline & & $80 \%$ or more occupied & 0.894 & \\
\hline & \multirow[t]{3}{*}{ Reservation options } & No reservation & 0.000 & \multirow[t]{3}{*}{1.000} \\
\hline & & Reservation (US\$ 3) & 0.459 & \\
\hline & & Reservation (US\$ 6) & 0.977 & \\
\hline \multirow{10}{*}{ Fee } & \multirow{4}{*}{ Daily use fees } & US\$ 9 daily use fee & 0.234 & \multirow{4}{*}{0.818} \\
\hline & & US\$ 6 daily use fee & 0.554 & \\
\hline & & US\$ 3 daily use fee & 1.000 & \\
\hline & & US\$ 0 daily use fee & 0.201 & \\
\hline & \multirow[t]{4}{*}{ Nightly fees } & US\$ 10 nightly fee & 0.620 & \multirow[t]{4}{*}{0.507} \\
\hline & & US\$ 8 nightly fee & 0.627 & \\
\hline & & US\$ 6 nightly fee & 0.535 & \\
\hline & & US\$ 4 nightly fee & 0.132 & \\
\hline & \multirow[t]{2}{*}{ Discount on third night stay } & No discount & 0.343 & \multirow[t]{2}{*}{0.277} \\
\hline & & $50 \%$ discount for third night & 0.614 & \\
\hline
\end{tabular}

Table 2 Relative main effect and beta weights

Over $90 \%$ of the respondents were interested in water-related recreational activities such as swimming (42\%) or fishing (52\%). Hiking (76\%) emerged as the most popular activity whereas horse riding and mountain biking were preferred by only a small number of respondents. Approximately three-fourth of the campers had gone on at least one other camping trip during the last 12-month period and over half the campers had gone for three or 
more trips. Based on these descriptive results it appears that campers in Shawnee National Forest are quite diverse and experienced. Next, we explain the results of campground choice exercises.

\section{Campground Choice Modeling Results}

The primary analysis approach associated with DCA is the estimation of the multinomial logit (MNL) models based on a maximum likelihood estimation technique (Ben-Akiva and Lerman, 1991). Recall that each respondent had to evaluate eight choice sets, each containing two campground descriptions along with the choice of not choosing either. Statistical details about MNL model estimation is described in extensive detail by Ben-Akiva and Lerman (1991) and Loiuviere et al., 2001. A more applied description of DCA and MNL model estimation is provided in Verma et al. (2001), Verma et al. (2002) and Verma and Plaschka (2003). Loiuviere et al. (2001) and Ben-Akiva and Lerman (1991) recommend that when estimating MNL models, experimental variables can be "effects-coded" to accurately estimate the relative impact on respondents' choices. The estimated MNL model was statistically significant at $5 \%$ level.

Table 2 shows the relative impact of each experimental attribute on campground choice decisions. We present normalized the estimated beta weights between "zero" and "one" based on the highest and lowest part worth utility of an attribute (This linear transformation allows us to easily compare the impact of one attribute or level with others without worrying about the meaning of the scale for estimated beta weights.). As recommended by Loiuviere et al. (2001), we estimated the relative main effect by subtracting the highest and lowest beta weights for a given attribute. The main affects allow us to compare the overall impact of changing the levels of attributes in campground choice against each other.

The numerical results presented in Table 2 are plotted in Figs. 2-5 to clearly illustrate campground choice patterns clearly. Fig. 2 shows the relative main effect of all experimental attributes and the aggregated impact of each of the three experimental constructs. Among the three constructs "capacity" accounts for $40 \%$ relative weight followed by $34 \%$ relative weight assigned on location-related attributes and $26 \%$ weight on fees. Perhaps the main effects of attributes are more illustrative which shows that reservation options, activities close to campground, campground location, daily use fee and occupancy are attributes with five highest weights. Discount on third night stay and the specific location of campsite within a campground had lowest relative impact of the choice of campground.

Fig. 3 shows the relative impact of location-related attributes on campground choice. Campers in Shawnee National Forest prefer campgrounds located close to rugged hills or unique geological formations compared to campgrounds located in green valley or near water mass. They also prefer campsites separated by bushes and trees. Among the four recreational activities considered, hunting was found to be least popular whereas physical activities were the most favorite followed by horse riding and water-related activates.

The relative preferences for the three attributes related to capacity are presented in Fig. 
4. It is very interesting to see the parabolic shape of the utility curves for both campground size and occupancy. The campers prefer either a very small or very large campground. Similarly, their either prefer very empty or very full campgrounds compared to options in the middle. On the other hand, utility for reservation options show that campers are willing and prefer to pay US\$ 6 for the option of reserving the campsite of their choice ahead of time.
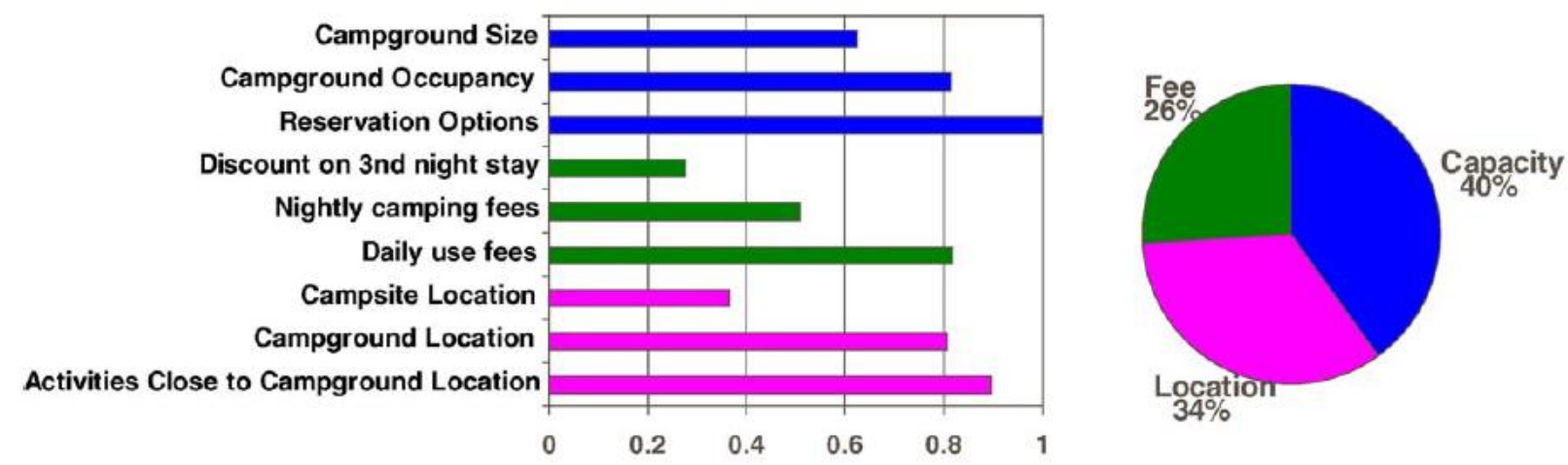

Fig. 2 Relative main effects of experimental constructs and determinant attributes.
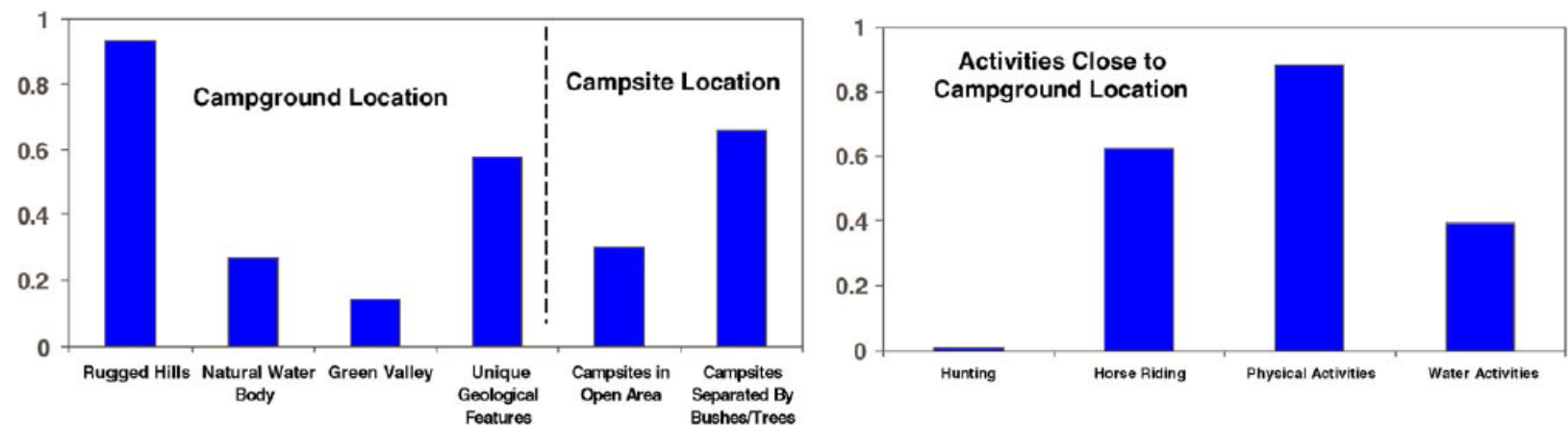

Fig. 3 Relative impact of location attributes on campground choice.

Fig. 5 shows the relative utilities of various pricing options. The campers prefer to pay a small (US\$ 3) fee for the day-use of the facilities compared to free use of facilities. Furthermore, they exhibit indifference in their preferences for paying between US\$ 6 and 10 as nightly fee for the use of campsite. There was a slight preference for receiving a $50 \%$ discount for staying a third night at the campground facilities.

The results presented in Figs. 2-5 and Table 2 has important implications for the design and development of new services within the Shawnee National Forest and also for day-to-day management and maintenance of existing facilities. The results presented above were programmed into an easy-to-use spreadsheet-based decision-support model for use by forest service officials. The spreadsheet allows the field managers to conduct various types of "whatif" analyses and consider the impact of potential managerial actions on the marketplace. For example, based on the results presented in Fig. 4 the spreadsheet will show that raising nightly fee from US\$ 8 to 10 will have minimum impact on the marketplace but changing daily use fee 

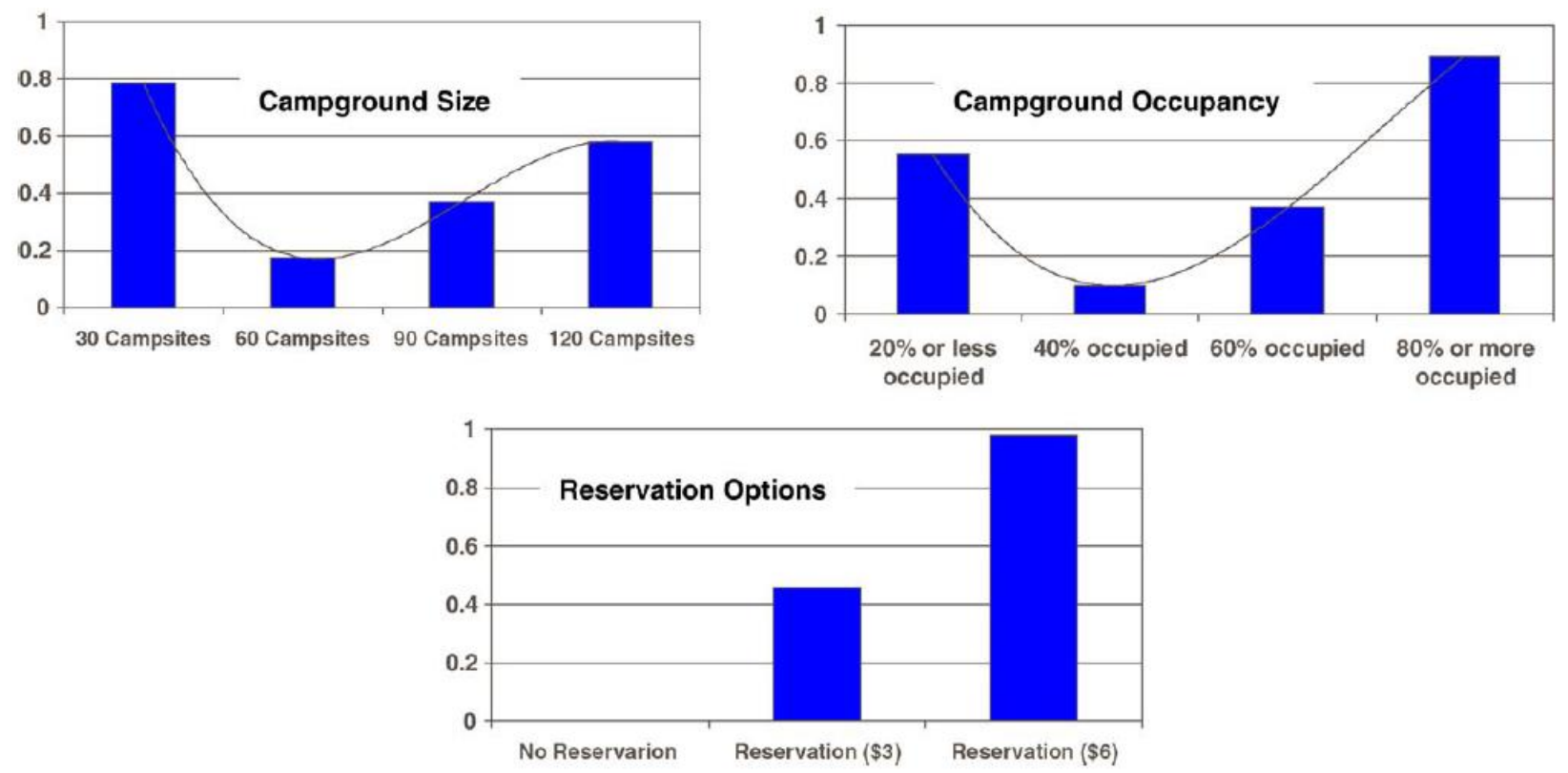

Fig. 4 Relative impact of capacity attributes on campground choice.
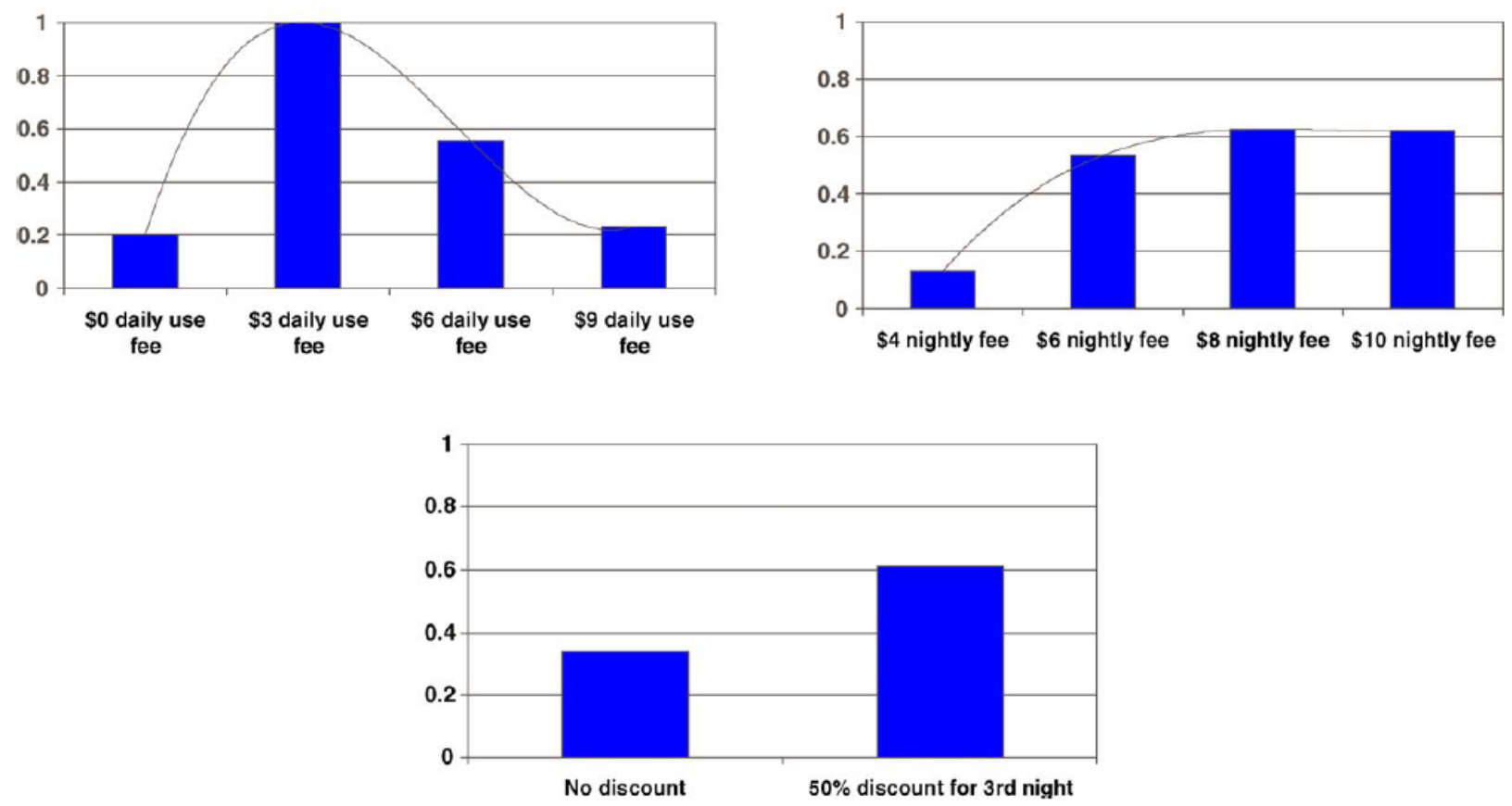

Fig. 5 Relative impact of user fee attributes on campground choice.

from US\$ 8 to 10 will have minimum impact on the marketplace but changing daily use fee from US\$ 3 to 6 might have a negative impact. A sample screenshot from a decision-support model is included in Fig. 6. 


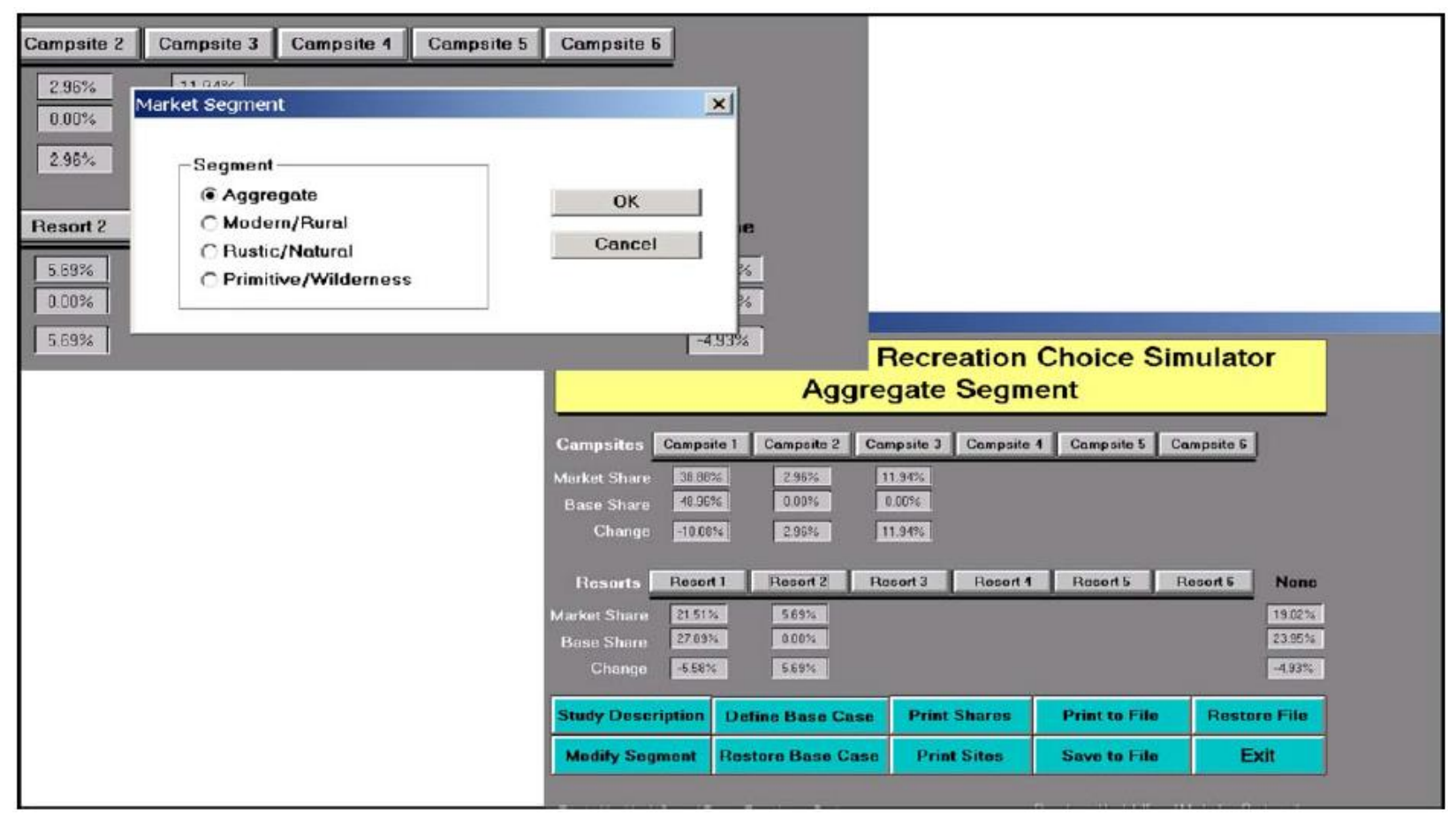

Fig 6. Sample decision support model screen-shot.

\section{Concluding Remarks}

As mentioned earlier, because of shrinking funding levels, deregulation and competition from for-profit companies and not-for-profit organizations, government agencies are experiencing increased pressure to maximize the limited resources available to them. In this paper, we have described and illustrated the use of market-utility-based approach used by the United State Forest Service to better understand the needs and preferences of their customers.

The case study presented in this paper demonstrates how visitors of a national forest trade-off between various features of the campground, the recreational activities available to them, with price and capacity constraints which choosing a campground to stay at. The results show an un-biased snapshot of users preferences, which can be used by forest service managers and officials when designing and developing new facilities. For example, the results show that the campgrounds developed near rugged hills or unique geological features where the campers can participate in physical activities and where campsites are separated by trees/bushes will be more popular then the ones in green valley or near a water mass. These results therefore guide "location planning" and eliminate the need for ad-hoc decision-making. Similarly the two capacity-related attributes provide guidance on the size of the campground developments. Developing a series of small campground or a few large campgrounds might be a better use of resources compared to several mid-size facilities.

Government and not-for-profit agencies always struggle to come-up with the appropriate pricing schemes for the use of their facilities. The results from our study show that campground users are willing to pay reasonable amount for day and night use of facilities and 
for the advance reservations. For example, while it is common to see campground nightly rates vary from US\$ 6 to 8 , the campers do not seem to mind paying US\$10. At the same time, they would prefer a discount for longer stay. Similarly campers are willing to pay US\$ 6 for advanced reservation options. While in our study, we only explored simple pricing mechanisms, the context seem to be ready for application of advanced revenue management techniques.

While our case study is far from being comprehensive, it provides an illustration for successful use of advanced econometric modeling in combination with a large-scale empirical work in designing more effective services.

\section{Acknowledgements}

The authors gratefully acknowledge the assistance of Pat York, John Dwyer, Herb Schroeder, Susan Stewart, Paul Gobster and other members of the USDA Forest Service, North Central Research Station, Evanston, IL office and members of the Shawnee National Forest, IL USDA Forest Service team. We would also like to acknowledge support from over 25 graduate students at DePaul University who served as interviewers and travelled more than $\mathbf{3 0 0}$ miles (twice) for 4-day trips to complete the field surveys. This study was supported by a research grant from USDA Forest Service.

\section{References}

Ben-Akiva, M., Lerman, S.R., 1991. Discrete Choice Analysis. MIT Press, Cambridge, MA.

Danaher, P.J., 1997. Using conjoint analysis to determine the relative importance of service attributes measured in customer satisfaction surveys. Journal of Retailing 73 (2), 235260.

Easton, F., Pullman, M.E., 2001. Optimizing service attributes: the seller's utility problem. Decision Sciences 32 (2), 1-25.

Goodale, J., Verma, R., Pullman, M.E., 2003. A market utility based model for capacity scheduling in mass services. Production and Operations Management 12 (2).

Green, P.E., Srinivasan, V., 1990. Conjoint analysis in marketing: new developments with implications for research and practice. Journal of Marketing 54 (October), 3-19.

Iqbal, Z., Verma, R., Baran, R., 2003. Understanding customer choices and preferences for transaction-based e-Services. Journal of Service Research 6 (1).

Keating, E.K., Frumkin, P., 2001. How to Assess Nonprofit Financial Performance. Working Paper. Northwestern University.

Loiuviere, J.J., Hensher, D., Swait, J., 2001. Stated Preference Methods. University Press, Cambridge. 
Louviere, J.J., Timmermans, H., 1990. Stated preference and choice models applied to recreation research: a review. Leisure Science 12, 9-32.

McFadden, D., 1986. The choice theory approach to market research. Marketing Science 5 (4), 275-297.

Pullman, M., Verma, R., Goodale, J., 2001. Service design and operations strategy formulation in multicultural markets. Journal of Operations Management 19 (2), 239-254.

Pullman, M.E., Moore, W.L., 1999. Optimal service design: Integrating marketing and operations perspective. International Journal of Service Industry Management 10 (2), 239-260.

Verma, R., Thompson, G.M., Moore, W.L., Louviere, J.J., 2001. Effective design of products/services: an approach based on integration of marketing and operations management decisions. Decision Sciences 32 (1), 165-193.

Verma, R., Plaschka, G., Louviere, J.L., 2002. Understanding customer choices: A key to successful management of hospitality services. Cornell Quarterly 43 (6), 15-24.

Verma, R., Plaschka, G., 2003. The art and science of customer choice modeling: Reflections, advances and managerial implications. Cornell Quarterly 44 (5-6), 156-165.

Verma, R., Thompson, G.M., Louviere, J.J., 1999. Configuring service operations based on customer needs and preferences. Journal of Service Research 1 (3), 262-274. 